\title{
Coinage Metal-Ethylene Complexes Supported by Tris(pyrazolyl)borates: A Computational Study
}

\author{
Abul B. Kazi,${ }^{\dagger}$ H. V. Rasika Dias, ${ }^{\ddagger}$ Sammer M. Tekarli, ${ }^{\S}$ Glenn R. Morello, ${ }^{\S}$ and \\ Thomas R. Cundari*,

\begin{abstract}
Department of Chemistry, University of Arkansas-Pine Bluff, Pine Bluff, Arkansas 71601, Department of Chemistry and Biochemistry, The University of Texas at Arlington, 700 Planetarium Place, Arlington, Texas 76019-0065, and Department of Chemistry, Center for Advanced Scientific Computing
\end{abstract} \\ and Modeling (CASCaM), University of North Texas, Box 305070, Denton, Texas 76203-5070
}

Received October 30, 2008

\begin{abstract}
Data from computational and experimental sources have been combined to address the bonding and structure of $\left[\mathrm{RB}\left(3-\left(\mathrm{R}^{1}\right), 5-\left(\mathrm{R}^{2}\right) \mathrm{Pz}\right)_{3}\right] \mathrm{M}\left(\mathrm{C}_{2} \mathrm{H}_{4}\right)$ complexes, where $\mathrm{M}=\mathrm{Cu}, \mathrm{Ag}, \mathrm{Au}$. $\mathrm{A} \kappa^{3}$ to $\kappa^{2}$ distortion of the scorpionate ligand was also studied. NMR properties were deemed to be the most useful in assessing the nature of the bonding in these complexes. Using computational recipes, ${ }^{13} \mathrm{C}$ chemical shifts accurately reproduced quantitative experimental values and trends as a function of metal, ligand, and substituent. $\mathrm{Au}$-ethylene complexes are found to be substantially "less $\pi$-complex" (T-shaped structure) in their bonding description versus $\mathrm{Ag}$ and $\mathrm{Cu}$ congeners, although the former are by no means entirely metallacyclopropane in their constitution. Combining the present calculations with prior contributions to coinage metal bonding leads us to propose that similarity of molecular structure among a congeneric series of coinage metal complexes reflects a principally ionic coinage metal-ligand bonding regime, while dissimilarity of structure within the series reflects a primarily covalent bonding regime.
\end{abstract}

\section{Introduction}

Olefin complexes of the coinage metals are a family of complexes that have been well-studied, and increasingly so in the past several years. ${ }^{1}$ The univalent coinage metal (group 11 - copper, silver, and gold) ions have been known to interact with olefins from the time of Winstein's research on the interaction of silver ions with olefins to current application of this chemistry in chromatographic separation. ${ }^{2}$ Silver-catalyzed partial oxidation of ethylene to ethylene oxide is a major industrial process. ${ }^{3}$ Ethylene is a ripening agent in plants, and the ethylene receptor of the metalloenzyme responsible for this activity is believed to be a copper center. ${ }^{4}$ Gold has been the target of recent novel syntheses, which have yielded $\mathrm{Au}$-ethylene adducts stable enough for X-ray crystallographic characterization. $^{5,6}$ For example, Dias' group has reported the synthesis of a tris-ethylene cation, $\left[\mathrm{Au}\left(\mathrm{C}_{2} \mathrm{H}_{4}\right)_{3}\right]^{+}{ }^{5}$ a the planar, spoke-wheel arrangement of the three ethylene ligands immediately suggests a potential for catalytic activity, for example, cyclotrimerization to cyclohexane. In another interesting species, Dias' group has reported the isolation of $\left[\mathrm{HB}\left(3,5-\left(\mathrm{CF}_{3}\right)_{2} \mathrm{Pz}\right)_{3}\right] \mathrm{Au}\left(\mathrm{C}_{2} \mathrm{H}_{4}\right)$ and $\left[\mathrm{HB}\left(3-\left(\mathrm{CF}_{3}\right), 5-(\mathrm{Ph}) \mathrm{Pz}\right)_{3}\right] \mathrm{Au}\left(\mathrm{C}_{2} \mathrm{H}_{4}\right)$ using fluorinated hydrotris(pyrazolyl)borate supporting ligands. ${ }^{6}$ What is especially

* Corresponding author. E-mail: t@unt.edu.

University of Arkansas-Pine Bluff.

$\div$ The University of Texas at Arlington.

$\S$ University of North Texas.

(1) (a) Dias, H. V. R.; Wu, J. Eur. J. Inorg. Chem. 2008, 509. (b) Dias, H. V. R.; Wu, J. Eur. J. Inorg. Chem. 2008, 2113. (c) See also: Dias, H. V. R.; Lovely, C. J. Chem. Rev. 2008, 108, 3223.

(2) Kaneti, J.; de Smet, L. C. P. M.; Boom, R.; Zuilhof, H.; Sudhölter, E. J. R. J. Phys. Chem. A 2002, 106, 11197.

(3) Barteau, M. A. Top. Catal. 2003, 22, 3.

(4) Kepczynski, J. Biotechnologia 2006, 36.

(5) (a) Dias, H. V. R.; Fianchini, M.; Cundari, T. R.; Campana, C. F. Angew. Chem., Int. Ed. 2008, 47, 556. (b) Flores, J. A.; Dias, H. V. R. Inorg. Chem. 2008, 47, 4448.

(6) Dias, H. V. R.; Wu, J. Angew. Chem., Int. Ed. 2007, 4641, 7814.

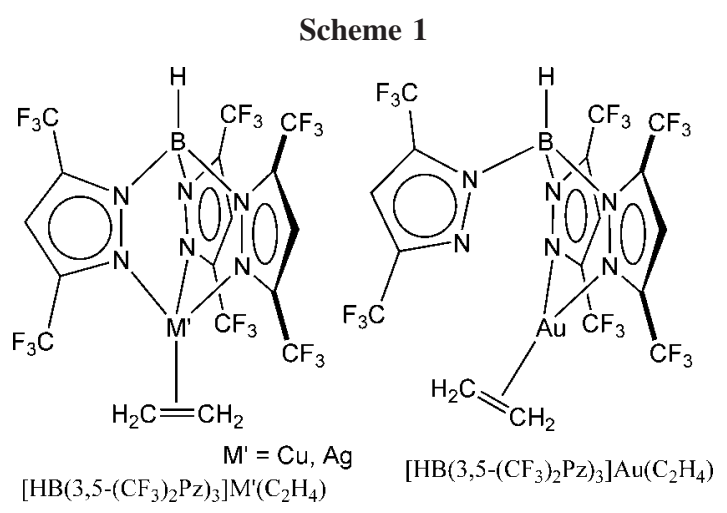

interesting in these complexes is the $\kappa^{2}$ coordination of the tris(pyrazolyl)borate ligand (i.e., one very long and two short $\mathrm{Au}-\mathrm{N}$ bond lengths), which thus deviates from the typical $\kappa^{3}$ coordination of scorpionate ligands. Intriguingly, the corresponding ethylene complexes of copper and silver supported by tris(pyrazolyl)borates (Tp) display $\kappa^{3}$ coordination in the solid state, Scheme $1 .{ }^{7,8}$

The dichotomy between $\kappa^{2} / \kappa^{3}$ coordination modes in the $\left[\mathrm{RB}\left(3-\left(\mathrm{R}^{1}\right), 5-\left(\mathrm{R}^{2}\right) \mathrm{Pz}\right)_{3}\right] \mathrm{M}\left(\mathrm{C}_{2} \mathrm{H}_{4}\right)$ complexes, Scheme 1 , is in contrast to the structural similarity observed for other families of coinage metal congeners our groups have studied, trisethylene complexes ${ }^{5 a}$ and the $\left[R B\left(3-\left(R^{1}\right), 5-\left(R^{2}\right) P z\right)_{3}\right] \mathrm{M}-\mathrm{CO}($ e.g.,

(7) (a) Thompson, J. S.; Harlow, R. L.; Whitney, J. F. J. Am. Chem. Soc. 1983, 105, 3522. (b) Dias, H. V. R.; Lu, H. L.; Kim, H. J.; Polach, A. A.; Goh, T. K. H. H.; Browning, R. G.; Lovely, C. J. Organometallics 2002, 21, 1466. (c) Dias, H. V. R.; Wang, X.; Diyabalange, H. V. K. Inorg. Chem. 2005, 44, 7322.

(8) (a) Dias, H. V. R.; Wang, X. Dalton Trans. 2005, 2985. (b) Dias, H. V. R.; Wang, Z.; Jin, W. Inorg. Chem. 1997, 36, 6205. 


\section{Scheme 2}

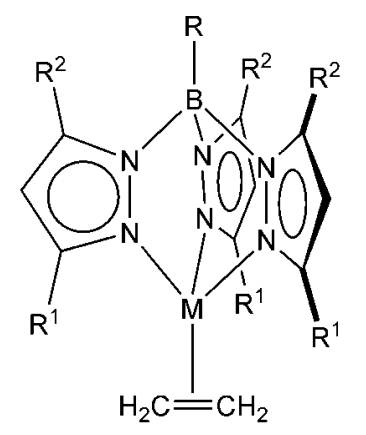

$\left[\mathrm{RB}\left(3-\left(\mathrm{R}^{1}\right), 5-\left(\mathrm{R}^{2}\right) \mathrm{Pz}\right)_{3}\right] \mathrm{M}\left(\mathrm{C}_{2} \mathrm{H}_{4}\right)$

$\left.\left[\mathrm{HB}\left(3,5-\left(\mathrm{CF}_{3}\right)_{2} \mathrm{Pz}\right)_{3}\right] \mathrm{M}-\mathrm{CO}\right) .{ }^{9,10}$ However, the $\mathrm{Au}$ analogue of the $\left[\mathrm{HB}\left(3,5-\left(\mathrm{CF}_{3}\right)_{2} \mathrm{Pz}\right)_{3}\right] \mathrm{M}-\mathrm{CNBu}{ }^{t}$ series shows significant $\mathrm{Au}-\mathrm{N}$ asymmetry. ${ }^{10}$ Alvarez's group has published an interesting computational study of the bonding in group 11 complexes, focusing on preference in coordination mode. ${ }^{11}$ In a previous experiment-theory analysis of the coinage metal-tris(ethylene) cations, the metal-ligand bonding in these complexes was described as predominantly ionic in nature, with the gold complex being the most covalent/less ionic among the triad. ${ }^{5 a}$

It is noteworthy that, although cationic copper, silver, and gold adducts of ethylene of the type $\left[\mathrm{M}\left(\mathrm{C}_{2} \mathrm{H}_{4}\right)\right]^{+}$have been investigated in detail by several groups using computational methods, studies of coinage metal ethylene adducts containing other ancillary ligands are very limited. ${ }^{12}$ These studies are typically limited to neutral molecules of the type $\mathrm{FM}\left(\mathrm{C}_{2} \mathrm{H}_{4}\right)(\mathrm{M}$ $=\mathrm{Cu}, \mathrm{Ag}, \mathrm{Au}$ ) or cationic complexes such as $\left[\mathrm{M}(\mathrm{bpy})\left(\mathrm{C}_{2} \mathrm{H}_{4}\right)\right]^{+13}$ and imply that ancillary ligands acutely affect the $\mathrm{M}-\mathrm{C}$ and $\mathrm{C}=\mathrm{C}$ bonds and the extent of $\pi$-bonding. To this end, we have conducted a study of the bonding and structure of $\left[\mathrm{RB}\left(3-\left(\mathrm{R}^{1}\right), 5-\right.\right.$ $\left.\left.\left(\mathrm{R}^{2}\right) \mathrm{Pz}\right)_{3}\right] \mathrm{M}\left(\mathrm{C}_{2} \mathrm{H}_{4}\right)$ complexes (Scheme 2) utilizing evaluations

(9) (a) Dias, H. V. R.; Goh, T. K. H. H. Polyhedron 2004, 23, 273. (b) Conry, R. R.; Ji, G.; Tipton, A. A. Inorg. Chem. 1999, 38, 906. (c) Churchill, M. R.; DeBoer, B. G.; Rotella, F. J.; Salah, O. M. A.; Bruce, M. I. Inorg. Chem. 1975, 14, 2051. (d) Imai, S.; Fujisawa, K.; Kobayashi, T.; Shirasawa, N.; Fujii, H.; Yoshimura, T.; Kitajima, N.; Moro-oka, Y. Inorg. Chem. 1998, 37, 3066. (e) Kiani, S.; Long, J. R.; Stavropoulos, P. Inorg. Chim. Acta 1997, 263, 357. (f) Dias, H. V. R.; Kim, H. J. Organometallics 1996, 15, 5374. (g) Kitajima, N.; Fujisawa, K.; Fujimoto, C.; Moro-oka, Y.; Hashimoto, S.; Kitagawa, T.; Toriumi, K.; Tatsumi, K.; Nakamura, K. J. Am. Chem. Soc. 1992, 114, 1277. (h) Dias, H. V. R.; Kim, H. J.; Lu, H. L.; Rajeshwar, K.; de Tacconi, N. R.; Derecskei-Kovacs, A.; Marynick, D. S. Organometallics 1996, 15, 2994. (i) Dias, H. V. R.; Jin, W. J. Am. Chem. Soc. 1995, 117, 11381. (j) Dias, H. V. R.; Lu, H. L. Inorg. Chem. 1995, 34, 5380 .

(10) Dias, H. V. R.; Jin, W. Inorg. Chem. 1996, 35, 3687.

(11) (a) Carvajal, M. A.; Novoa, J. J.; Alvarez, S. J. Am. Chem. Soc. 2004, 126, 1465-1477, See also the following papers for a pertinent discussion of four-coordination in transition metal complexes: (b) Cirera, J.; Ruiz, E.; Alvarez, S. Inorg. Chem. 2008, 47, 2871. (c) Cirera, K.; Alemany, P.; Alvarez, S. Chem.-Eur. J. 2004, 10, 190.

(12) (a) Krossing, I.; Reisinger, A. Angew. Chem., Int. Ed. 2003, 42, 5725. (b) Schröder, D.; Schwarz, H.; Hrsák, J.; Pyykkö, P. Inorg. Chem. 1998, 37, 624. (c) Schröder, D.; Wesendrup, R.; Hertwig, R. H.; Dargel, T. K.; Grauel, H.; Koch, W.; Bender, B. R.; Schwarz, H. Organometallics 2000, 19, 2608. (d) Guo, B. C.; Castleman Jr. Chem. Phys. Lett. 1991, 181, 16, and references therein. (e) Hertwig, R. H.; Koch, W.; Schröder, D.; Schwarz, H.; Hrsák, J.; Schwerdtfeger, P. J. Phys. Chem. 1996, 100, 12253. (f) Tai, H. C.; Krossing, I.; Seth, M.; Deubel, D. V. Organometallics 2004, 23, 2343.

(13) (a) Kim, C. K.; Lee, K. A.; Kim, C. K.; Lee, B.-S.; Lee, H. W. Chem. Phys. Lett. 2004, 391, 321. (b) Bera, J. K.; Samuelson, A. G.; Chandrasekhar, J. Organometallics 1998, 17, 4136. (c) Budzelaar, P. H. M.; Timmermans, P. J. J. A.; Mackor, A.; Baerends, E. J. J. Organomet. Chem. 1987, 331, 397. (d) Haeffner, F.; Brinck, T.; Haeberlein, M.; Moberg, C. J. Mol. Struct. (THEOCHEM) 1997, 397, 39. (e) Cinellu, M. A.; Minghetti, G.; Cocco, F.; Stoccoro, S.; Zucca, A.; Manassero, M.; Arca, M. Dalton Trans. 2006, 5703 . of their electronic structure, thermodynamics, and spectral features.

\section{Computational Methods}

Unless stated otherwise, quantum calculations employed the Gaussian 03 package. ${ }^{14}$ The BP86 functional was employed in conjunction with the Stevens $\left(\mathrm{SBK}^{15}\right)$ valence basis sets and effective core potentials for the coinage metals. The SBK scheme utilizes a semicore approximation for transition metals. The standard SBK valence basis set is triplet-zeta for transition metals. The valence basis sets of the transition metals were augmented with the Couty-Hall $\mathrm{p}$ functions ${ }^{16}$ (fully uncontracted) and the $\mathrm{f}$ polarization functions published by Frenking and co-workers. ${ }^{17}$ The following basis sets were utilized to model main group atoms: ethylene carbon and ligand nitrogen atoms, 6-311+G(d); remaining (nonligated) main group elements, 6-31G. This combination of basis sets and density functional was selected after considerable calibration versus the binding enthalpies, computed geometries, and NMR and vibrational spectral features of coinage metal ions and mono-, bis-, and tris-ethylene complexes. ${ }^{5,18}$

All complexes modeled were closed-shell (diamagnetic) species and were modeled within the restricted Kohn-Sham formalism. All systems were fully optimized, and analytic calculations of the energy Hessian were performed to confirm species as minima and to obtain calculated enthalpies and free energies (determined using unscaled vibrational frequencies) in the gas phase at $1 \mathrm{~atm}$ and 298.15 K. The calculated NMR properties employed the GIAO approximation. $^{19}$

\section{Results and Discussion}

1. Structure of $\left[\mathrm{RB}\left(3-\left(\mathrm{R}^{1}\right), 5-\left(\mathrm{R}^{2}\right) \mathrm{Pz}\right)_{3}\right] \mathrm{M}\left(\mathrm{C}_{2} \mathrm{H}_{4}\right)$ Complexes. a. Carbon-Carbon Bond Length of Ethylene Ligand. Before delving into the computational results, it is worth noting that the current computational model (BP86 functional plus extended basis sets) accurately reproduces experimental data with respect to metal-ligand bond lengths and the geometry within the ethylene ligand, Table 1. This level of theory was used in a previous study of tris-ethylene complexes of the coinage metal ions, ${ }^{5 a}$ and others have indicated the particular utility of BP86 for coinage metal chemistry. ${ }^{20}$

The CC bond distance has been extensively evaluated as a measure of metal/olefin interaction. Within the Dewar-ChattDuncanson (DCD) model, ${ }^{21}$ both ligand-to-metal $\sigma$-donation from $\pi_{\mathrm{CC}}$ and metal-to-ligand $\pi$-backbonding to the $\pi^{*}{ }_{\mathrm{CC}}$ orbital will lengthen the ethylene $\mathrm{CC}$ bond, which is expected to range from $\sim 1.34 \AA$ ( $\pi$-complex, T-shaped structure) to $\sim 1.54 \AA$ (metallacyclopropane). The average calculated $\mathrm{CC}$ distance in the $\left[\mathrm{RB}\left(3-\left(\mathrm{R}^{1}\right), 5-\left(\mathrm{R}^{2}\right) \mathrm{Pz}\right)_{3}\right] \mathrm{Cu}\left(\mathrm{C}_{2} \mathrm{H}_{4}\right)$ complexes is $1.389(4) \AA$, where the number in parentheses denotes the sample standard deviation, Table 1 . The $\mathrm{CC}$ bond length of free ethylene at this

(14) Frisch, M. J.; Pople, J. A. Gaussian 03, revision C.02; Gaussian, Inc.: Wallingford, CT, 2004.

(15) Stevens, W. J.; Krauss, M.; Basch, H.; Jasien, P. G. Can. J. Chem. 1992, 70,612 .

(16) Couty, M.; Hall, M. B. J. Comput. Chem. 1996, 17, 1359.

(17) Frenking, G.; Ehlers, A. W.; Boehme, M.; Dapprich, S.; Gobbi, A.; Hoellwarth, A.; Jonas, V.; Koehler, K. F.; Stegmann, R.; Veldkamp, A. Chem. Phys. Lett. 1993, 208, 111.

(18) A more complete analysis of the data used in calibration of the theoretical models is available in the Supporting Information of ref 5a.

(19) Gauss, J.; Stanton, J. F. Adv. Chem. Phys. 2002, 123, 355

(20) See, for example: (a) Dietz, O.; Rayon, V. M.; Frenking, G. Inorg. Chem. 2003, 42, 4977. (b) Nemcsok, D.; Wichmann, K.; Frenking, G. Organometallics 2004, 23, 3640.

(21) (a) Dewar, M. J. S. Bull. Soc. Chim. Fr. 1951, C71. (b) Chatt, J.; Duncanson, L. A. J. Chem. Soc. 1953, 2939. 
Table 1. Calculated and Experimental Metric and Vibrational Data for Tris(pyrazolyl)borate-Coinage Metal(I)-Ethylene Complexes ${ }^{a}$

\begin{tabular}{|c|c|c|c|c|c|c|c|c|c|c|c|}
\hline $\mathrm{MN}^{b}$ & $\mathrm{MN}^{b}$ & $\mathrm{MN}^{b}$ & $P^{i}$ & Asym $^{d}$ & $\mathrm{CC}^{b}$ & $\mathrm{MC}^{b}$ & $\tau^{e}$ & subs & refcode $^{c}$ & $v(\mathrm{CC})^{f}$ & $\mathrm{BR}^{g}$ \\
\hline \multicolumn{12}{|c|}{ Cu Complexes } \\
\hline 2.00 & 2.00 & 2.24 & 154.3 & $6.7 \%$ & 1.396 & $2.02(2 \times)$ & 162 & $3,5-\mathrm{H}$ & calc & 1518 & $\mathrm{BMe}$ \\
\hline 2.03 & 2.03 & 2.37 & 160.0 & $9.2 \%$ & 1.387 & $2.05(2 \times)$ & 164 & $3-\mathrm{CF}_{3}$ & calc & 1534 & BH \\
\hline 2.04 & 2.15 & 2.21 & & $4.2 \%$ & disorder $^{h}$ & $1.99 / 2.05$ & & $3-C_{3}$ & $M I T W U H^{7 b}$ & $? ? ?$ & $B H$ \\
\hline 2.03 & 2.03 & 2.32 & 157.5 & $7.9 \%$ & 1.387 & $2.05(2 \times)$ & 164 & $3-\mathrm{CF}_{3}$ & calc & 1531 & $\mathrm{BMe}$ \\
\hline 2.03 & 2.03 & 2.27 & & $6.5 \%$ & 1.334 & $2.03(2 \times)$ & & $3-C_{3}$ & $S A V V A N^{7 c}$ & ??? & $B M e$ \\
\hline 2.03 & 2.04 & 2.33 & 157.5 & $8.0 \%$ & 1.385 & $2.05 / 6$ & 165 & $3,5-C_{3}$ & calc & 1536 & BH \\
\hline 2.03 & 2.15 & 2.15 & & $3.4 \%$ & disorder & $1.98(2 \times)$ & & $3,5-C F_{3}$ & $M I T W I V^{7 b}$ & ??? & $B H$ \\
\hline 1.99 & 2.01 & 2.87 & 178.6 & $21.9 \%$ & 1.390 & $2.03(2 \times)$ & 164 & $3,5-\mathrm{CF}_{3}$ & calc & 1527 & $\mathrm{BMe}$ \\
\hline \multicolumn{12}{|c|}{ Ag Complexes } \\
\hline 2.25 & 2.25 & 2.48 & 159.1 & $5.7 \%$ & 1.386 & $2.24(2 \times)$ & 167 & $3,5-\mathrm{H}$ & calc & 1536 & $\mathrm{BMe}$ \\
\hline 2.30 & 2.31 & 2.52 & 158.5 & $5.2 \%$ & 1.379 & $2.26(2 \times)$ & 168 & $3-\mathrm{CF}_{3}$ & calc & 1547 & BH \\
\hline 2.30 & 2.30 & 2.50 & 158.2 & $4.9 \%$ & 1.379 & $2.26(2 \times)$ & 168 & $3-\mathrm{CF}_{3}$ & calc & 1548 & $\mathrm{BMe}$ \\
\hline 2.27 & 2.32 & 2.45 & & $4.0 \%$ & 1.340 & $2.28(2 \times)$ & & $3-C F_{3}$ & ref 35 & ??? & $B M e$ \\
\hline 2.33 & 2.34 & 2.40 & & $1.6 \%$ & 1.298 & $2.29 / 31$ & & $3,5-C F_{3}$ & ref $8 b$ & ??? & $B H$ \\
\hline 2.33 & 2.35 & 2.59 & 158.1 & $6.0 \%$ & 1.376 & $2.28 / 9$ & 168 & $3,5-\mathrm{CF}_{3}$ & calc & 1554 & $\mathrm{BMe}$ \\
\hline \multicolumn{12}{|c|}{ Au Complexes } \\
\hline 2.19 & 2.19 & 2.80 & 173.6 & $14.7 \%$ & 1.432 & $2.11(2 \times)$ & 154 & $3,5-\mathrm{H}$ & calc & 1488 & $\mathrm{BMe}$ \\
\hline 2.23 & 2.24 & 2.74 & 175.1 & $12.1 \%$ & 1.421 & $2.13(2 \times)$ & 157 & $3-\mathrm{CF}_{3}$ & calc & 1499 & $\mathrm{BMe}$ \\
\hline 2.24 & 2.24 & 2.82 & 176.6 & $13.8 \%$ & 1.421 & $2.13(2 \times)$ & 157 & $3-\mathrm{CF}_{3}$ & calc & 1498 & BH \\
\hline 2.24 & 2.26 & 2.86 & 175.6 & $14.4 \%$ & 1.418 & $2.13 / 4$ & 158 & $3,5-\mathrm{CF}_{3}$ & calc & 1502 & BH \\
\hline 2.22 & 2.22 & 2.71 & & $11.9 \%$ & 1.380 & $2.10 / 1$ & & $3,5-C F_{3}$ & ref 6 & ??? & BH \\
\hline 2.23 & 2.27 & 2.98 & 175.6 & $16.9 \%$ & 1.418 & $2.13 / 4$ & 158 & $3,5-\mathrm{CF}_{3}$ & calc & 1502 & $\mathrm{BMe}$ \\
\hline
\end{tabular}

${ }^{a}$ Bond lengths in angstroms; angles in deg. Values calculated using the BP86 functional and the following basis sets: ethylene C's and N atoms, 6-311+G(d); remaining (nonligated) main group elements, 6-31G; coinage metal, Stevens relativistic ECPs ${ }^{15}$ and attendant valence triple- $\zeta$ basis sets plus Frenking's f polarization function ${ }^{17}$ and the Couty-Hall $\mathrm{p}$ function ${ }^{16}$ (fully uncontracted). ${ }^{b} \mathrm{MN}=$ the three bond lengths from the coinage metal to the Tp nitrogens; $\mathrm{MC}$ and $\mathrm{CC}$ refer to the ethylene fragment. ${ }^{c}$ Experimental values in italics; calcd $\mathrm{BH}$-decorated Tp complexes in bold; calcd $\mathrm{BMe}$-decorated $\mathrm{Tp}$ complexes in roman. ${ }^{d}$ Asym is a measure of asymmetry in the three $\mathrm{M}-\mathrm{N}(\mathrm{Tp})$ distances and is defined as Asym $=$ $\operatorname{stdev}(\mathrm{MN}) /$ mean $(\mathrm{MN}) * 100 \%$. ${ }^{e}$ " $\tau$ " is the improper $\mathrm{C}=\mathrm{C}-\mathrm{H} \cdots \mathrm{H}$; a $\tau$ of $180^{\circ}$ defines a perfectly planar ethylene carbon. Experimental values were not included, as hydrogen atoms positions resulting from X-ray studies were not deemed to be reliable. ${ }^{f} v(\mathrm{CC})$ is the calculated CC stretching frequency in $\mathrm{cm}^{-1}$; ???, value of CC stretching frequency of ligated ethylene is not reported. ${ }^{g}$ BR denotes the group attached to the boron atom of the scorpionate ligand (see Scheme2). "Disorder" indicates that disorder at ethylene carbon precludes measurement of this metric parameter. ${ }^{i} P$ measures the planarity of the coinage metal coordination sphere for calculated structures and is measured via the $\mathrm{Ct}-\mathrm{CM}-\mathrm{N} \cdots \mathrm{N}$ improper torsional angle $\left(180^{\circ}\right.$ for fully planar), where $\mathrm{Ct}=\mathrm{C}=\mathrm{C}$ centroid, $\mathrm{CM}=$ coinage metal, and $\mathrm{N}=$ two closest ligating $\mathrm{N}$ atoms of scorpionate.

level of theory is $1.338 \AA$, ${ }^{5 a}$ an $\sim 4 \%$ lengthening of $\mathrm{CC}$ bond upon coordination to copper. The average $\mathrm{CC}$ distances for the $\left[\mathrm{RB}\left(3-\left(\mathrm{R}^{1}\right), 5-\left(\mathrm{R}^{2}\right) \mathrm{Pz}\right)_{3}\right] \mathrm{Ag}\left(\mathrm{C}_{2} \mathrm{H}_{4}\right)$ and $\left[\mathrm{RB}\left(3-\left(\mathrm{R}^{1}\right), 5-\left(\mathrm{R}^{2}\right) \mathrm{Pz}\right)_{3}\right]-$ $\mathrm{Au}\left(\mathrm{C}_{2} \mathrm{H}_{4}\right)$ complexes are 1.380(4) and 1.422(6) $\AA$, respectively. The average $\mathrm{CC}$ distance in the $\left[\mathrm{RB}\left(3-\left(\mathrm{R}^{1}\right), 5-\left(\mathrm{R}^{2}\right) \mathrm{Pz}\right)_{3}\right] \mathrm{Cu}-$ $\left(\mathrm{C}_{2} \mathrm{H}_{4}\right)$ complexes is thus marginally longer than that in the $\left[\mathrm{RB}\left(3-\left(\mathrm{R}^{1}\right), 5-\left(\mathrm{R}^{2}\right) \mathrm{Pz}\right)_{3}\right] \mathrm{Ag}\left(\mathrm{C}_{2} \mathrm{H}_{4}\right)$ analogues and significantly shorter than that in the $\left[\mathrm{RB}\left(3-\left(\mathrm{R}^{1}\right), 5-\left(\mathrm{R}^{2}\right) \mathrm{Pz}\right)_{3}\right] \mathrm{Au}\left(\mathrm{C}_{2} \mathrm{H}_{4}\right)$ congeners.

b. Carbon-Carbon Stretching Frequency of Ethylene Ligand. The $\mathrm{CC}$ stretching frequency, $v_{\mathrm{CC}}$, is another popular indicator of the nature of the metal/olefin interaction. ${ }^{1}$ Measurement of $v_{\mathrm{CC}}$ is hindered by its low intensity in infrared spectra and must therefore often be extracted from Raman experiments, which can be challenging on metastable coinage metal ethylene complexes. However, one must consider $v_{\mathrm{CC}}$ in conjunction with others pieces of evidence, metric, theoretical, spectroscopic, etc., as Hebben et al. have pointed out that the $v_{\mathrm{CC}}$ stretch may couple with $\delta\left(\mathrm{CH}_{2}\right)$ modes. $^{22}$ In a study of $\left[\mathrm{M}\left(\mathrm{C}_{2} \mathrm{H}_{4}\right)_{3}\right]^{+}$, BP86calculated and experimental $\mathrm{CC}$ stretching frequencies compared very well. ${ }^{5 \mathrm{a}}$ From the data in Table 1 , the average calculated $v_{\mathrm{CC}}$ values for $\left[\mathrm{RB}\left(3-\left(\mathrm{R}^{1}\right), 5-\left(\mathrm{R}^{2}\right) \mathrm{Pz}\right)_{3}\right] \mathrm{M}\left(\mathrm{C}_{2} \mathrm{H}_{4}\right)$ are $1529(6)$, $1546(7)$, and $1498 \mathrm{~cm}^{-1}$ for $\mathrm{M}=\mathrm{Cu}, \mathrm{Ag}$, and $\mathrm{Au}$, respectively. As with the $\mathrm{CC}$ bond distances discussed above, the calculated $v_{\mathrm{CC}}$ does not change monotonically as one descends the group 11 triad, but rather gold complexes have the lowest calculated $\mathrm{CC}$ stretching frequencies while the silver values are the highest (or the smallest changes from free ethylene $v_{\mathrm{CC}}=1632 \mathrm{~cm}^{-1}$ (calcd), 1623 (expt)).

(22) Hebben, N.; Himmel, H.-J.; Eickerling, G.; Herrmann, C.; Reiher, M.; Herz, V.; Presnitz, M.; Scherer, W. Chem.-Eur. J. 2007, 13, 10078.
2. Calculated NMR Spectra of $\left[R B\left(3-\left(R^{1}\right), 5-\left(R^{2}\right) P z\right)_{3}\right]-$ $\mathbf{M}\left(\mathbf{C}_{2} \mathbf{H}_{4}\right)$. NMR analysis of bonding in transition metal olefin complexes has proven to be a valuable tool, primarily ${ }^{1} \mathrm{H}$ and ${ }^{13} \mathrm{C}$ chemical shifts, but also ${ }^{1} J_{\mathrm{CH}}$ coupling constants. ${ }^{1} \mathrm{We}$ focused on calculated ${ }^{13} \mathrm{C}$ chemical shifts in the present study given the bigger, more flexible basis sets used for $\mathrm{C}$ versus $\mathrm{H}$ atoms on the ethylene ligand and the greater resolution of ${ }^{13} \mathrm{C}$ NMR spectra as compared to those for ${ }^{1} \mathrm{H}$. Test calculations of ${ }^{1} J_{\mathrm{CH}}$ did not reveal much sensitivity of this parameter to metal modification, a result borne out of the experimental data, ${ }^{1,5,6}$ thus not justifying the extra expense of this calculation.

Before using computations to probe ${ }^{13} \mathrm{C}$ chemical shifts for various $\left[\mathrm{RB}\left(3-\left(\mathrm{R}^{1}\right), 5-\left(\mathrm{R}^{2}\right) \mathrm{Pz}\right)_{3}\right] \mathrm{M}\left(\mathrm{C}_{2} \mathrm{H}_{4}\right)$ and the implications of changes in this spectroscopic parameter, the various boundaries must be defined. Note that in Table 2 and throughout this discussion, the calculated chemical shifts are referenced to that for tetramethylsilane (TMS) at the same level of theory. At one extreme, free ethylene has a calculated $\delta\left({ }^{13} \mathrm{C}\right)$ of $128.5 \mathrm{ppm}$ at the current level of DFT theory, which compares with an experimental value of $123.4 \mathrm{ppm}$ in $\mathrm{CD}_{2} \mathrm{Cl}_{2}$. The upfield end of the ${ }^{13} \mathrm{C}$ chemical shift scale is more nebulous in terms of assessing the balance between a $\pi$-complex $\left(\sim \mathrm{sp}^{2}\right.$ carbon) and metallacyclopropane $\left(\sim \mathrm{sp}^{3}\right.$ carbon $)$. For example, cyclopropane has a calculated $\delta\left({ }^{13} \mathrm{C}\right.$ ) of $0.2 \mathrm{ppm}$ (ca. 0 to $-4 \mathrm{ppm}$ depending on solvent, $\left.\operatorname{expt}^{24}\right)$. The ${ }^{13} \mathrm{C}$ chemical shifts of other threemembered ring organics are, however, substantially downfield from cyclopropane: ethylene oxide (45.0 ppm, calcd; ca. $41 \mathrm{ppm}$, $\operatorname{expt}^{23}$ ) and ethylene sulfide (24.9 ppm, calcd; ca. 17-19 ppm depending on solvent, $\operatorname{expt}^{23}$ ). To further calibrate the coinage metal complexes studied here, a literature survey of ${ }^{13} \mathrm{C} \mathrm{NMR}$ chemical shifts was conducted. To best isolate the most reliable systems, we focused on neutral, monometallic, monoethylene, 
Table 2. BP86-Calculated NMR Chemical Shifts Populations for Tris(pyrazolyl)borate-Coinage Metal(I)-Ethylene Complexes ${ }^{a}$

\begin{tabular}{|c|c|c|c|c|}
\hline subs & refcode ${ }^{c}$ & $\mathrm{BR}$ & ${ }^{13} \mathrm{C}^{b}$ & ${ }^{1} \mathrm{H}$ \\
\hline \multicolumn{5}{|c|}{ Free Ethylene $e^{5 a}$} \\
\hline & calc & & 128.5 & 5.7 \\
\hline & $\operatorname{expt}\left(\mathrm{CD}_{2} \mathrm{Cl}_{2}\right.$ & & 123.4 & 5.4 \\
\hline \multicolumn{5}{|c|}{ Copper Complexes } \\
\hline $3,5-\mathrm{H}$ & calc & $\mathrm{BMe}$ & 74.6 & 3.8 \\
\hline $3-\mathrm{CF}_{3}$ & calc & $\mathrm{BMe}$ & 88.7 & 4.7 \\
\hline $3-\mathrm{CF}_{3}$ & calc & BH & 88.5 & 4.6 \\
\hline $3-\mathrm{CF}_{3}$ & $M I T W U H^{7 b}$ & $B H$ & 85.8 & $4.8-5.0$ \\
\hline $3-\mathrm{CF}_{3}$ & $S A V V A N^{7 c}$ & $B M e$ & 85.4 & 4.8 \\
\hline $3,5-\mathrm{CF}_{3}$ & calc & BH & 91.7 & 4.7 \\
\hline $3,5-C F_{3}$ & $M I T W I V^{7 b}$ & $B H$ & 89.5 & $4.9-5.0$ \\
\hline $3,5-\mathrm{CF}_{3}$ & calc & $\mathrm{BMe}$ & 89.3 & 3.9 \\
\hline \multicolumn{5}{|c|}{ Silver Complexes } \\
\hline $3,5-\mathrm{H}$ & calc & BMe & 83.1 & 4.5 \\
\hline $3-\mathrm{CF}_{3}$ & calc & $\mathrm{BMe}$ & 96.1 & 5.2 \\
\hline $3-\mathrm{CF}_{3}$ & ref 20 & $\mathrm{BMe}$ & 104 & 5.5 \\
\hline $3-C_{2} F_{5}$ & $K A Y L I G^{8 a}$ & $B M e$ & 105.5 & 5.5 \\
\hline $3,5-C F_{3}$ & $N O B D E N^{8 b}$ & BH & 104.9 & 5.6 \\
\hline $3,5-\mathrm{CF}_{3}$ & calc & $\mathrm{BMe}$ & 103.3 & 5.0 \\
\hline \multicolumn{5}{|c|}{ Gold Complexes } \\
\hline $3,5-\mathrm{H}$ & calc & BMe & 57.0 & 3.4 \\
\hline $3-\mathrm{CF}_{3}$ & calc & $\mathrm{BH}$ & 69.1 & 3.9 \\
\hline $3-\mathrm{CF}_{3}$ & calc & $\mathrm{BMe}$ & 69.5 & 4 \\
\hline $3,5-\mathrm{CF}_{3}$ & calc & $\mathrm{BH}$ & 73.7 & 3.9 \\
\hline $3,5-C F_{3}$ & ref 6 & $B H$ & 63.7 & $3.6-3.8$ \\
\hline $3,5-\mathrm{CF}_{3}$ & calc & $\mathrm{BMe}$ & 74.3 & 3.7 \\
\hline
\end{tabular}

${ }^{a}$ Bond lengths in angstroms; angles in deg. Values calculated using the BP86 functional and the following basis sets: ethylene C's and N atoms, 6-311+G(d); remaining (nonligated) main group elements, 6-31G; coinage metal, Stevens relativistic ECPs and attendant valence triple- $\zeta$ basis sets plus Frenking $\mathrm{f}$ polarization function and Couty-Hall $\mathrm{p}$ function (fully uncontracted). ${ }^{b}$ NMR chemical shifts are calculated as described in Computational Methods. Chemical shifts are calculated using the GIAO method and are references to calculated chemical shifts for TMS at the same level of theory used to describe the metal complexes. ${ }^{c}$ Experimental values in italics; calculated $\mathrm{BH}$-decorated $\mathrm{Tp}$ complexes in bold; calculated BMe-decorated Tp complexes in roman.

diamagnetic complexes found in the $\mathrm{CCDC}^{24}$ for which $R<$ $5 \%$. This survey yielded ${ }^{13} \mathrm{C}$ NMR chemical shifts for 30 complexes (some complexes did and some did not have magnetically equivalent ethylene carbons) with a median of 60 ppm, a sample mean and standard deviation of $57 \pm 18 \mathrm{ppm}$, and a range from $25 \mathrm{ppm}\left(\left[\mathrm{Ni}\left({ }^{i} \mathrm{Pr}_{2} \mathrm{Im}\right)_{2}\left(\mathrm{C}_{2} \mathrm{H}_{4}\right)\right]\right)^{25}$ to $105 \mathrm{ppm}$ $\left(\left[\mathrm{HB}\left(3,5-\left(\mathrm{CF}_{3}\right)_{2} \mathrm{Pz}\right)_{3}\right] \mathrm{Ag}\left(\mathrm{C}_{2} \mathrm{H}_{4}\right)\right) .{ }^{8 \mathrm{~b}}$ In terms of a DCD bonding analysis, one may define the latter as the "most $\pi$-complex" and the $N$-heterocyclic carbene complex as the "most metallacyclopropane" in their bonding character.

The calculated ${ }^{13} \mathrm{C}$ chemical shifts, Table 2, range from 75 to 89 to 89 ppm for $\mathrm{Cu}, 83$ to 96 to 103 for silver, and 57 to 70 to $74 \mathrm{ppm}$ for gold $\mathrm{Tp}$ complexes (with a BMe moiety) upon the addition of a first and then a second $\mathrm{CF}_{3}$ group to pyrazolyl arms. Several points of interest emerge from the data. First, the calculations are in accord with experimental chemical shifts that have been reported, Table 2. Second, the addition of the first $\mathrm{CF}_{3}$ (to the 3-position) more substantially shifts the ethylene chemical shift upfield versus the addition of the second $\mathrm{CF}_{3}$ group (to the 5-position). This result can be rationalized in that the inductive effect of the $\mathrm{CF}_{3}$ in the 5-position must be

(23) Experimental values were obtained through the compendium of spectral properties available within the SciFinder database. CAS registry numbers are as follows: ethylene oxide (75-21-8), ethylene sulfide (42012-2), and cyclopropane (75-19-4).

(24) Cambridge Crystallographic Data Center (CCDC): Allen, F. H.; Davies, J. E.; Galloy, J. J.; Johnson, O.; Kennard, O.; Macrae, C. F.; Mitchell, E. M.; Smith, J. M.; Watson, D. G. J. Chem. Comput. Sci. 1991, 187.

(25) Schaub, T.; Radius, U. Chem.-Eur. J. 2005, 11, 5024. transmitted through a greater number of bonds to the ethylene carbons than that for the same substituent in the 3-position of the scorpionate ligand. Third, the calculated range of $\delta$ is greatest for silver (20 ppm) versus copper (14 ppm) or gold (17 ppm). Fourth, the calculated chemical shifts are closest to free ethylene for the silver complexes. The gold complexes, on the other hand, display the lowest chemical shifts (or most upfield shifted ${ }^{13} \mathrm{C}$ signals relative to free ethylene) among the coinage metal systems studied here. Hence, the NMR calculations support (and extend) the previous structural and vibrational analyses: gold complexes are the least $\pi$-complex/most metallacyclopropane in their nature, and vice versa for the silver congeners. Indeed, the accumulated evidence points to $\operatorname{Tp} A g\left(\mathrm{C}_{2} \mathrm{H}_{4}\right)$ complexes as being the "most $\pi$-complex" among all of the neutral ethylene complexes studied or surveyed here.

3. Asymmetry in $\mathbf{M}-\mathbf{N}$ Bonding, $\kappa^{3} \rightarrow \kappa^{2}$ Distortion. a. Trends as a Function of Metal. We now probe a structural incongruity that is particular to the $\left[\mathrm{RB}\left(3-\left(\mathrm{R}^{1}\right), 5-\left(\mathrm{R}^{2}\right) \mathrm{Pz}\right)_{3}\right]-$ $\mathrm{M}\left(\mathrm{C}_{2} \mathrm{H}_{4}\right)$ family of complexes, the asymmetry of the three $\mathrm{N}-\mathrm{M}$ bond lengths. To quantify the asymmetry within the scorpionate complexes studied here, we define Asym as stdev(MN)/average $(\mathrm{MN}) * 100 \%$. Calculated Asym values are largest for $\mathrm{Au}$ (14(2)\%), least for $\mathrm{Ag}(6(1) \%)$, with $\mathrm{Cu}$ intermediate $(8(1) \%){ }^{26}$ As with other calculated and experimental metrics, $\mathrm{Ag}$ and $\mathrm{Cu}$ are more similar with Au being more different.

Two points are germane with respect to greater distortion to $\kappa^{2}-\mathrm{Tp}$ coordination for $\mathrm{Au}$ (ethylene) complexes. First, the deformation is distinct from a Jahn-Teller distortion, ${ }^{27}$ which is structurally manifested in a similar manner, cf., $\mathrm{d}^{9}-\mathrm{Cu}$ (II) complexes $\left[\mathrm{HB}(3-(t-\mathrm{Bu}), 5-(\mathrm{Me}) \mathrm{Pz})_{3}\right] \mathrm{CuCl}^{28}{ }^{2}\left[\mathrm{HB}\left(3,5-(i-\mathrm{Pr})_{2} \mathrm{Pz}\right)_{3}\right]-$ $\mathrm{CuOOCMe}_{2} \mathrm{Ph},{ }^{29}$ and $\left[\mathrm{HB}\left(3,5-(i-\mathrm{Pr})_{2} \mathrm{Pz}\right)_{3}\right] \mathrm{CuSCPh}_{3} .{ }^{30}$ All metal ions studied in the present work are formally $\mathrm{d}^{10}$ using typical electron counting rules. Second, the distortion to $\kappa^{2}$ coordination is also a function of the ligand. For example, $\left[\mathrm{RB}\left(3-\left(\mathrm{R}^{1}\right), 5-\right.\right.$ $\left.\left.\left(\mathrm{R}^{2}\right) \mathrm{Pz}\right)_{3}\right] \mathrm{M}-\mathrm{CO}$ complexes are uniformly found in the $\kappa^{3}$ coordination mode. On the other hand, the stronger $\sigma$-donor and weaker $\pi$-acid, $\mathrm{CN}^{t} \mathrm{Bu}$, yields essentially a $\kappa^{1}$-Tp ligation model for a gold complex! ${ }^{10}$ As the $\kappa^{3} \rightarrow \kappa^{2}$ distortion marks a divergence between gold complexes and the lighter coinage metals, we further analyze this disparity and its chemical implications.

Where do gold-scorpionate-ethylene complexes lie within the $\pi$-complex/metallacyclopropane spectrum? For the least electron-deficient scorpionate, $\left[\mathrm{MeB}(\mathrm{Pz})_{3}\right] \mathrm{Au}\left(\mathrm{C}_{2} \mathrm{H}_{4}\right)$, which has the lowest $\delta\left({ }^{13} \mathrm{C}\right)$ among the complexes studied here, the NMR shift is $57 \mathrm{ppm}$ for the ethylene carbon atoms, essentially identical to the sample median and sample averages found in our literature survey (vide supra). Moreover, $\left[\mathrm{MeB}(\mathrm{Pz})_{3}\right]-$ $\mathrm{Au}\left(\mathrm{C}_{2} \mathrm{H}_{4}\right)$ is only ca. $30 \mathrm{ppm}$ downfield of the $N$-heterocyclic carbene complex $\left[\mathrm{Ni}\left({ }^{i} \operatorname{Pr}_{2} \operatorname{Im}\right)_{2}\left(\mathrm{C}_{2} \mathrm{H}_{4}\right)\right],{ }^{25}$ the most upfield ${ }^{13} \mathrm{C}$ chemical shift we found in our survey. The chemical shift is a complicated physical property, dependent on a multitude of factors. However, whether using metal complexes or organics as benchmarks, the $\mathrm{Au}$-ethylene complexes remain substantially

(26) For the copper complexes, $\left[\mathrm{MeB}\left(3,5-\left(\mathrm{CF}_{3}\right)_{2} \mathrm{Pz}\right)_{3}\right] \mathrm{Cu}\left(\mathrm{C}_{2} \mathrm{H}_{4}\right)$ has a very large asymmetry in its $\mathrm{Cu}-\mathrm{N}_{\mathrm{Tp}}$ bond lengths, likely due to steric effects from the 3,5 substitution on the Tp ring and the small size of the copper metal. Exclusion of this outlier yields an average Asym for the remaining TpCu complexes of $8(1) \%$.

(27) Cucurull-Sanchez, L.; Maseras, F.; Lledos, A. Inorg. Chem. Commun. 2000, 3, 590.

(28) Yoon, K.; Parkin, G. Polyhedron 1995, 14, 811.

(29) Kitajima, N.; Katayama, T.; Fujisawa, K.; Iwata, Y.; Moro-Oka, Y. J. Am. Chem. Soc. 1993, 115, 7872.

(30) Randall, D. W.; George, S. D.; Hedman, B.; Hodgson, K. O.; Fujsawa, K.; Solomon, E. I. J. Am. Chem. Soc. 2000, 122, 11620. 
less $\pi$-complex in their bonding description than Ag congeners, although they are no means entirely metallacyclopropane in their constitution.

How then does the $\kappa^{3} \rightarrow \kappa^{2}$ distortion fit into a refined understanding of coinage metal binding? As asserted above, this distortion is distinct from a Jahn-Teller distortion, and further we do not feel that it is indicative of even a second-order Jahn-Teller effect. Carvajal et al. ${ }^{11}$ have analyzed the coordination number preference for $\mathrm{d}^{10}$ group 11 ions. Upon going from three- to four-coordinate ( $\kappa^{2}$ to $\kappa^{3}$ Tp coordination in the present case), four energetic components to the formation energy must be evaluated: (a) the deformation energy to pyramidalize the trigonal planar reactants; (b) the energy required to stretch the $\mathrm{M}-\mathrm{L}$ bond lengths to reflect the expected increase in bond length with metal coordination number; (c) a preorganization term needed to get the fourth ligand (i.e., a pyrazolate arm) into its optimal binding conformation; and (d) the interaction energy between the fourth ligand and the metal ion. Several key points emerged from this seminal study. First, the interaction energy (component d) is the key component of the overall formation energy, and the magnitude of this is most influenced by the atomic charges of the metal and ligand fragments. Second, the deformation energy of gold (component a) is larger than that for copper and silver. ${ }^{11}$ It is interesting to note that for the present complexes studied there is a strong linear correlation $\left(R \approx 0.9\right.$, positive slope) between the degree of $\kappa^{2}$ to $\kappa^{3}$ distortion (as measured by Asym) and distortion of the metal coordination sphere from trigonal planarity (as measured by the $\mathrm{Ct}-\mathrm{CM}-\mathrm{N} \cdots \mathrm{N}$ improper torsional angle, where $\mathrm{Ct}=$ $\mathrm{C}=\mathrm{C}$ centroid, $\mathrm{CM}=$ coinage metal, and $\mathrm{N}=$ two closest ligating $\mathrm{N}$ atoms of scorpionate; see Table 1 for calculated values of this metric); that is, as the complexes approach $\kappa^{3}$ ligation, the metal coordination geometry becomes increasingly pseudotetrahedral. With respect to the present family of complexes, we expect that the energetic components (a) and (b) are small, and furthermore likely not to discriminate among coinage metal ions in terms of coordination preferences. In another very intriguing paper, Casarin et al. have used DFT to evaluate the energetics of tris(pyrazolyl)methane complexes with silver(I) and copper(I) ions. Their studies for these charged model complexes show the $\kappa^{2}$ to $\kappa^{3}$ interconversion to be an essentially barrierless process. ${ }^{31}$ Aullón et al. ${ }^{32}$ have likewise demonstrated facile interconversion for $\mathrm{d}^{8}$ complexes through a combination of DFT calculations and crystallographic analyses. Finally, fluxional behavior is indicated in solution for TpAu complexes, which equilibrate the pyrazolate arms even for complexes that are $\kappa^{2}$ in the solid state. ${ }^{6}$

The present work in conjunction with that of Casarin et al., ${ }^{32}$ Aullón et al., ${ }^{33}$ and solution fluxionality ${ }^{6}$ imply that thermodynamic considerations trump kinetics in the $\kappa^{2}$ to $\kappa^{3}$ distortion for the TpM complexes that are the subject of this research. To address the binding enthalpy components, model simulations were carried out involving charged $\left(\mathrm{M}^{+}+\mathrm{Pz}^{-} \rightarrow \mathrm{M}(\mathrm{Pz})\right)$ and neutral $\left(3 \mathrm{M}(\mathrm{Pz}) \rightarrow \mathrm{M}_{3} \mathrm{Pz}_{3}\right)$ exemplars. The binding enthalpies for pyrazolate anion to coinage metal ion are $-184(\mathrm{Cu}),-161$ $(\mathrm{Ag})$, and $-191 \mathrm{kcal} / \mathrm{mol}^{33}$ The trimerization energies are -180 $(\mathrm{Cu}),-140(\mathrm{Ag})$, and $-179(\mathrm{Au}) \mathrm{kcal} / \mathrm{mol}$. The calculations, whether using charged or neutral reactants, yield roughly the same result, and one that mirrors the metric and spectroscopic

(31) Casarin, M.; Forrer, D.; Garau, F.; Pandolfo, L.; Pettinari, C.; Vittadini, A. J. Phys. Chem. A 2008, 112, 6723.

(32) Aullón, G.; Esquius, G.; Lledós, A.; Maseras, F.; Pons, J.; Ros, J. Organometallics 2004, 23, 5530 .

(33) These calculations were done at the B3LYP/CEP-31G(d) level of theory as in ref 35 . data presented earlier; that is, copper and gold are more similar, while silver is more disparate. Assuming such a result translates to the binding of a third pyrazolate arm, the analysis implies that bindings of copper (i.e., distinctly $\kappa^{3}$ coordination observed and calculated) and gold (i.e., $\kappa^{2}$ coordination observed and calculated) are similar. Thus, the preference for $\kappa^{2}$ coordination for $\mathrm{TpAu}$ (olefin) complexes should have its origin in the greater energy required to deform the coordination geometry of gold (trigonal planar to pseudotetrahedral) that coordination of a third pyrazolate arm would entail.

b. Trends as a Function of Scorpionate Ligand. Two ligand effects were evaluated with respect to $\kappa^{3} \rightarrow \kappa^{2}$ distortion. First, the effect of changing the substituent on boron between $\mathrm{Me}$ and $\mathrm{H}$ was evaluated. Second, the Tp arms were substituted. Trifluoromethyl $\left(\mathrm{CF}_{3}\right)$ was used in the simulations, and attention was focused on the 3- and 5-positions of the Tp arms as these are the most experimentally relevant.

In a previous paper, Dias et al. observed a wide divergence in coordination mode when replacing the typical $\mathrm{B}-\mathrm{H}$ substituent of scorpionate ligands with a $\mathrm{B}-\mathrm{Ph}$ group. ${ }^{34}$ The latter complex was $\kappa^{2}$, that is, one of the Tp arms deligated, and it may be possible that metal $-\pi$-interactions compensated for the loss of the third $\mathrm{M}-\mathrm{N}$ interaction and thus provided a driving force for $\kappa^{2}$ distortion. In the present case, agostic $(\mathrm{C}-\mathrm{H} \cdots \mathrm{M})$ interaction could conceivably incite $\kappa^{3} \rightarrow \kappa^{2}$ distortion. To assess this possibility, a series of geometry optimizations was initiated with one arm of the scorpionate noncoordinated and the B-methyl substituent proximal to the coinage metal. In no case was a structure isolated that was lower in energy than the complexes elaborated in Table 1. Upon BP86 geometry optimization, the complexes reverted to the geometry listed in Table 1 or to a higher-order stationary point.

The success of the Dias group in isolating $\left[\mathrm{RB}\left(3-\left(\mathrm{R}^{1}\right), 5-\right.\right.$ $\left.\left.\left(\mathrm{R}^{2}\right) \mathrm{Pz}\right)_{3}\right] \mathrm{M}\left(\mathrm{C}_{2} \mathrm{H}_{4}\right)$ coinage metal complexes ${ }^{6,7,8}$ coincides with the use of fluorinated substituents, for example, $\mathrm{CF}_{3}, \mathrm{C}_{2} \mathrm{~F}_{5}$, or $\mathrm{C}_{3} \mathrm{~F}_{7}$. To assess the impact of increasing fluorination upon calculated properties, we evaluated $\left[\mathrm{RB}\left(3-\left(\mathrm{R}^{1}\right), 5-\left(\mathrm{R}^{2}\right) \mathrm{Pz}\right)_{3}\right] \mathrm{M}-$ $\left(\mathrm{C}_{2} \mathrm{H}_{4}\right)$ complexes for all three coinage metals with $3-\mathrm{CF}_{3}$ and 3,5- $\left(\mathrm{CF}_{3}\right)_{2}$ substitution and compared these to parent complexes. Changes in Asym are difficult to interpret, and indeed all calculated metrics need to be viewed with care given their narrow variance for a given metal, Table 1 . Adding $\mathrm{CF}_{3}$ groups to the Tp arms yields calculated minima with higher $v_{\mathrm{CC}}$ and shorter $\mathrm{CC}$ bond lengths. The calculations yield the reasonable suggestion that greater withdrawing power for the substituted tris(pyrazolyl)borate ligand yields a description of the metal/ ethylene interaction that is more like a $\pi$-complex ( $\mathrm{T}$-shaped structure).

Inspection of the data in Table 1 shows a very small difference in the $\mathrm{CC}$ bond length and stretching frequency as well as $\tau$ and Asym when comparing the "BH"- and "BMe"substituted scorpionates. One exception to this generalization is the large change in Asym (21.9\% and $8.0 \%)$ for $[\mathrm{MeB}(3,5-$ $\left.\left.\left(\mathrm{CF}_{3}\right)_{2} \mathrm{Pz}\right)_{3}\right] \mathrm{Cu}\left(\mathrm{C}_{2} \mathrm{H}_{4}\right)$ and $\left[\mathrm{HB}\left(3,5-\left(\mathrm{CF}_{3}\right)_{2} \mathrm{Pz}\right)_{3}\right] \mathrm{Cu}\left(\mathrm{C}_{2} \mathrm{H}_{4}\right)$, respectively, Table 1 . In light of the similarity of the other metrics (CC bond length, $v_{\mathrm{CC}}$ and $\tau$ ), we ascribe this greater distortion in the former to steric conflict between the $5-\mathrm{CF}_{3}$ and the $\mathrm{Me}-\mathrm{B}$ substituents. To test this assertion, we compared the calculated geometries of $\left[\mathrm{MeB}\left(3-\left(\mathrm{CF}_{3}\right) \mathrm{Pz}\right)_{3}\right] \mathrm{Cu}\left(\mathrm{C}_{2} \mathrm{H}_{4}\right)$ and $\left[\mathrm{HB}\left(3-\left(\mathrm{CF}_{3}\right)-\right.\right.$ $\left.\mathrm{Pz})_{3}\right] \mathrm{Cu}\left(\mathrm{C}_{2} \mathrm{H}_{4}\right)$ complexes. The calculated Asym in $\mathrm{Cu}-\mathrm{N}$ bond lengths was similar in these less-congested complexes, $7.9 \%$ and $9.2 \%$, respectively, values commensurate with solid-state crystallographic data, Table 1 . Hence, calculations imply that steric hindrance between substituents at the 5-positions of the 
Tp pyrazolate arms and at the boron atom can enhance the $\kappa^{3}$ $\rightarrow \kappa^{2}$ distortion.

\section{Summary and Conclusions}

Analysis of $\left[\mathrm{RB}\left(3-\left(\mathrm{R}^{1}\right), 5-\left(\mathrm{R}^{2}\right) \mathrm{Pz}\right)_{3}\right] \mathrm{M}\left(\mathrm{C}_{2} \mathrm{H}_{4}\right)$ complexes, $\mathrm{M}=$ $1+$ coinage metal ion, has been made using DFT methods to address (a) where these $\mathrm{d}^{10}$ complexes fit in the pantheon of transition metal ethylene complexes, (b) where to place them in the $\pi$-complex/metallacyclopropane spectrum, and (c) implications of an interesting $\kappa^{3} \rightarrow \kappa^{2}$ distortion seen in TpAu(ethylene) complexes. Such issues are given greater importance by the recent growth in interest in coinage metals for applications in catalysis, optoelectronics, biology, and materials science. ${ }^{1-5}$ One point to emerge from the present research is that in terms of structural properties, these $\mathrm{d}^{10}$ ethylene complexes are consistent with more common examples incorporating early middle transition metals. Alternatively, perhaps these data suggest that metrics such as CC bond length are not the most sensitive measures of metal-olefin bonding. Similar dissatisfaction with the use of $\mathrm{CC}$ stretching frequencies emerges from this research. One of the current authors has substantial experience with the arduous nature of extracting $v_{\mathrm{CC}}$ from Raman spectroscopy. ${ }^{5 a}$ Moreover, Hebben et al..$^{23}$ demonstrate that $v_{\mathrm{CC}}$ and $\delta\left(\mathrm{CH}_{2}\right)$ are coupled, further complicating the extraction of unambiguous chemical information from shifts in $v_{\mathrm{CC}}$.

NMR properties were deemed the most useful for assessing the bonding. Calculated ${ }^{13} \mathrm{C}$ chemical shifts of ethylene carbons reproduced experimental values quite well, quantitatively and qualitatively as a function of metal, ligand, and substituent. $\mathrm{TpAg}$-ethylene complexes are the most downfield ( $\pi$-like) in terms of their $\delta\left({ }^{13} \mathrm{C}\right)$. For $\operatorname{TpAu}\left(\mathrm{C}_{2} \mathrm{H}_{4}\right)$, which has the lowest $\delta\left({ }^{13} \mathrm{C}\right)$ among the complexes studied here, the NMR shift is 57 $\mathrm{ppm}$, identical to the sample average found in our literature survey. The chemical shift is a complicated physical property, dependent on a multitude of factors. However, the $\delta\left({ }^{13} \mathrm{C}\right)$ corroborate the structural data in that $\mathrm{Au}$-ethylene complexes remain substantially less $\pi$-complex in their bonding description than do Ag congeners, although they are by no means entirely metallacyclopropane in their constitution.

Combining our present calculations with prior contributions to coinage metal bonding ${ }^{11,32}$ leads us to propose that similarity of molecular structure among a congeneric series of coinage metal complexes reflects a major ionic coinage metal-ligand bonding regime, while dissimilarity of structure within the series reflects a primarily covalent bonding regime. Tris-ethylene complexes have a similar structure for the copper, silver, and gold derivatives, as do the pyrazolate trimers reported by the Omary and Dias groups ${ }^{35}$ we thus quantify the present family coinage metal complexes as predominantly ionic in their comportment. On the other hand, the present $\mathrm{TpM}$ (ethylene) complexes are more structurally dissimilar, which is especially reflected in the $\kappa^{2}$ distortion. As such, our model assigns this family of complexes as being more covalent in their coinage metal-ligand bonding between the coinage metals with the Tp and ethylene ligands.

Of course, one must be careful as supporting ligation will impact the nature of the bonding. For example, the observations made here for $\mathrm{TpM}$ (ethylene) are different from those made for TpM-CO species. ${ }^{9,10}$ Cyclo- $\{$ M(pyrazolate $\left.)\right\}_{3}$ complexes and related trimers display similar structure throughout the coinage metal triad, ${ }^{35}$ which implies a primarily ionic metal-ligand bond description in our model. Of course, ligand constraints or metallophilicity may partially contribute to the structural similarity among the cyclo- $\{$ M(pyrazolate $)\}_{3}$ series. Additionally, cognizance must be taken of the impact of steric factors upon structure, as was discussed above for $\left[\mathrm{MeB}\left(3,5-\left(\mathrm{CF}_{3}\right)_{2}-\right.\right.$ $\left.\mathrm{Pz})_{3}\right] \mathrm{Cu}\left(\mathrm{C}_{2} \mathrm{H}_{4}\right)$. Sterics may explain the similarity in bonding among the $\mathrm{TpM}-\mathrm{CO}$ series, or perhaps it is a result of the greater $\pi$-acid nature of $\mathrm{CO}$ versus ethylene making the resulting carbonyl complex more ionic in their metal-ligand bonding. Indeed, it is the paradigm shift from viewing $\mathrm{d}^{10}$ metal ions as "innocent", catalytically, structurally, photochemically, to being seen as chemically flexible entities for which ligand/substituent effects can be used to coarse- and fine-tune their properties that has led to the tremendous growth in interest in their study by experimentalists. In this vein, more examples of congeneric families of coinage metal ion complexes would be welcome as they may not only reveal fundamental insight into the bonding of $\mathrm{d}^{10}$ transition metal ions, but also reveal new ways to harness their potential for the numerous important applications for which their chemistry is currently being pursued.

Acknowledgment. T.R.C. acknowledges the U.S. Department of Education for their support of CASCaM. Calculations employed the UNT computational chemistry resource, whose purchase was supported by a CRIF grant from the U.S. National Science Foundation (CHE-0342824). T.R.C. acknowledges the NSF (CHE-0701247) for supporting his contribution. A.B.K. would like to acknowledge the UAPB administration and the UAPB Department of Chemistry for providing computational facilities. H.V.R.D. thanks the Welch Foundation (grant Y-1289) for financial support of this research.

Supporting Information Available: A complete citation for ref 14 , plus coordinates for all DFT-optimized geometries. This material is available free of charge via the Internet at http://pubs.acs.org.

\section{OM8010454}

(34) Dias, H. V. R.; Wu, J.; Wang, X.; Rangan, K. Inorg. Chem. 2007, $46,1960$.

(35) (a) Tekarli, S. M.; Cundari, T. R.; Omary, M. A. J. Am. Chem. Soc. 2008, 130, 1669. (b) Grimes, T.; Omary, M. A.; Dias, H. V. R.; Cundari, T. R. J. Phys. Chem. A 2006, 110, 5823. (c) Omary, M. A.; Rawashdeh-Omary, M. A.; Gonser, M. W. A.; Elbjeirami, O.; Grimes, T.; Cundari, T. R.; Diyabalanage, H. V. K.; Gamage, C. S. P.; Dias, H. V. R. Inorg. Chem. 2005, 44, 8200. 